\title{
Psychosocial aspects of type 1 diabetes in Latino- and Asian-American youth
}

\author{
Kajal K. Gandhi' ${ }^{1}$ Tom Baranowski², Barbara J. Anderson ${ }^{3}$, Nidhi Bansal ${ }^{1}$ and Maria J. Redondo'
}

Latino and Asian-Americans represent the fastest growing immigrant populations in the United States. We aimed to review the current knowledge on the psychosocial factors that influence type 1 diabetes (T1D) care, education, and outcomes in Latino and Asian-American youth immigrants in the United States, as well as culturally sensitive programs to address health disparities. We conducted a narrative, conceptual review of studies on T1D in Latino and Asian-American youth and relevant studies in type 2 diabetes and adults. Approximately $50 \%$ of both Latino and Asian-American youth with T1D are in suboptimal glycemic control. Socioeconomic status, literacy, English proficiency, acculturation, access to health care, family functioning, mental health, and nutrition influence T1D care and outcomes. However, the degree to which these complex, inter-related and dynamic factors affect long-term T1D outcomes is largely unknown. Culturally sensitive programs for Latino or Asian-American youth with T1D are scarce in the United States. Research is needed among Latino and Asian-American youth with T1D so that comprehensive, culturally sensitive diabetes education, and care programs can be developed to decrease disparities in the health burden of these groups.

atino and Asian-American youth populations are increas-ing in the United States (1). Understanding the factors that are related to type 1 diabetes (T1D) education, care and outcomes among these groups will inform strategies to meet their needs within the existing health system.

This is a narrative, conceptual literature review on T1D outcomes among Latino and Asian-American youth. Although the focus is on T1D, due to the paucity of research, relevant findings on type 2 diabetes (T2D) and among adults are also included. We first describe demographics, socioeconomic characteristics, acculturation (i.e., the process of immigrants adapting to the host culture), and traditional values of Latinos and Asian-Americans in the United States. Next, the relationships of these characteristics with health are presented, followed by the health burden among Latino and Asian-American youth with T1D. Particularly, socioeconomic status (SES), poverty, health care access, health literacy, English proficiency, acculturation, family functioning, mental health, and nutrition in the Latino and Asian-American groups in the United States in relation with T1D are reviewed. We finally examine initiatives on culturally sensitive health delivery to improve T1D outcomes.

"Hispanic" and "Latino" are terms commonly applied to the same population. The confusion between "race" and "nationality" led early authors to consider the term "Hispanic" to define a person from a country of Spanish origin, with "Latinos" in the United States originating from a Latin-American country in the Western Hemisphere only, reflecting nationality and not language, culture, or race (2). The US Census Report defines Hispanic or Latino as a person of Cuban, Mexican, Puerto Rican, South- or Central-American descent, or other Spanish culture regardless of race (3). Many studies use the terms interchangeably. In this review, we favor the term "Latino" except when referring to a particular study wherein the authors used the name "Hispanic".

The 2014 US Census Reports indicated that $63 \%$ of Latinos were Mexican in origin (4), but also included CentralAmerican (7.9\%), South-American (5.5\%), Cuban-American (3.5\%), or Spanish-American (1.3\%) origins, among others. This heterogeneity must be considered when interpreting results that aggregate these groups (3). "Asian", which is considered a race category, is also diverse, including Chinese-, Indian-, Filipino, and Vietnamese-Americans, among many others (5). These large, fast growing and diverse populations deserve an informed and evolved approach to address health education and care, and ultimately reduce their health burdens.

\section{LATINOS AND ASIAN-AMERICANS IN THE UNITED STATES Demographics and Socioeconomics}

In 2010, approximately 40 million people in the United States were foreign-born, accounting for $\sim 13 \%$ of the US population (1). Substantial increases in Asian and Hispanic immigration occurred in recent decades, faster than other ethnic or racial groups $(3,5)$. The Hispanic-American population grew at four

'Division of Pediatric Endocrinology and Metabolism, Department of Pediatrics, Texas Children's Hospital/Baylor College of Medicine, Houston, Texas; ${ }^{2}$ Children's Nutrition Research Center, Baylor College of Medicine, Houston, Texas; ${ }^{3}$ Division of Psychology, Department of Pediatrics, Baylor College of Medicine, Houston, Texas. Correspondence: Maria J. Redondo(redondo@bcm.edu)

Received 1 May 2015; accepted 18 February 2016; advance online publication 10 August 2016. doi:10.1038/pr.2016.87 


\section{Review | Gandhiet al.}

times the rate of the overall US population from 2000 to 2010 (3). The Asian-American population increased by $43 \%$ in that time (5). In $2014,21 \%$ of children in the United States were native to the United States with at least one foreign-born parent (6). Specifically, 16\% native and 25\% foreign-born AsianAmerican children; and 57\% native and $41 \%$ foreign-born Hispanic children had at least one foreign-born parent (7).

Poverty disproportionately affects Hispanics and AsianAmericans, with $23 \%$ and $12 \%$ of these groups, respectively, being below the poverty level, compared with $10 \%$ of NonHispanic Whites (NHW) in the United States (8). In 2010, approximately 6.1 million of all poverty-stricken children in the United States were Hispanic and over one third were born of immigrant parents (9).

\section{Acculturation}

Acculturation is the process by which an immigrant group adopts the cultural patterns of a host population (10). Cultural patterns can involve attitudes, lifestyle practices, relationships, values, and self-identification (10). Once thought to be unidimensional, acculturation has many dimensions, including practices (such as language, food or friend preference), values and self-identification (11). Immigrant children, who tend to be more acculturated than their parents, can create a family "acculturation gap" (12). An acculturation gap may result in parents becoming overprotective of their adolescents to maintain cultural values (13), and/or parents being dependent on the adolescent to navigate through society (14). Similar findings have been reported among Asian-Indian and other AsianAmerican families $(15,16)$. This cultural identity struggle may affect family dynamics and relationships, and cause parentchild value discrepancies, resulting in conflict, decreased communication, and depression (14,17-19).

The relationship between SES and acculturation is bidirectional and dynamic $(20,21)$. Greater acculturation status tends to be associated with higher SES and, conversely, increased SES can intensify acculturation $(22,23)$. However, these characteristics may change over time and thus, confound study measures $(21,24,25)$.

\section{Values and Family Dynamics in Latino and Asian-Americans}

Hispanic cultural values include family closeness and loyalty (termed "familismo"), traditional gender association (in which the male tends to make family decisions, termed "machismo", and the female runs the household, termed "marianismo") and respect toward elders (termed "respeto") (26), more so than NHW youth (27). "Familismo" has been further delineated into "supportive familismo" (i.e., family closeness and loyalty), "obligation familismo" (i.e., responsibility to other family members), and "referent familismo" (i.e., agreement between own and family's traditions and expectations) (28). Acculturation is a complex, dynamic, and heterogeneous process that can modulate family values $(29,30)$.

Similarly, the Asian culture tends to favor deference for parental authority, follow traditional gender roles and encourage family unity $(17,31,32)$.
However, stereotyping should be avoided as not only racial, and ethnic groups are considerably heterogeneous, but there are also individual differences, and values and behaviors presented as associated with a culture are often not shared by many of its members. In addition, values and behaviors of Latinos and Asian-Americans can transform during the acculturative process.

\section{FACTORS ASSOCIATED TO HEALTH AMONG LATINOS AND ASIAN-AMERICANS}

\section{SES, Health Care Access, Literacy, English Proficiency, and} Acculturation

Children in poverty are at risk for environmental hazards, lack of adequate health insurance, lower physical, socioemotional, and cognitive well-being (33). US Census Reports show that approximately $19 \%$ of Hispanics lacked health care coverage in 2013 (34). Hispanic and Asian-American children were more likely to be uninsured as compared to Black youth (35). Access to health care and having a regular provider was lower among Asian-Americans and Hispanics than NHW (36-39). Limited English proficiency was particularly prevalent among AsianAmerican and Latino adults, as compared to NHW (40), which obstructs access to care in all racial/ethnic groups $(37,41)$. Poor parental literacy was associated with worse health outcomes in their children (42). Hispanics had the lowest health literacy rate among all US racial/ethnic groups (43), and both Asians and Hispanics had lower health literacy than Whites (41). Individuals with a combination of low health literacy and limited English proficiency were the most vulnerable to adverse health outcomes (41).

The "Latino mortality paradox" states that, although the Latino population tends to have a lower SES, all-cause mortality rates are lower compared to NHW in the United States (44-46). This paradox has been attributed to immigrants being generally healthier than those who stay in their native country, thus lowering the mortality rate of this group in the United States (termed the "healthy migrant effect"), or to older Latinos returning to their native country before their death, decreasing their mortality rate in the United States (termed the "salmon bias") $(44,46)$. However, healthier behaviors could also play a role (47). Alcohol consumption and smoking were less frequent among Latinos than NHW after controlling for SES (44). On the other hand, acculturation may increase obesity, smoking, and alcohol consumption (44), possibly moderating the "Latino mortality paradox". Immigrant Asians and Hispanics also had lower mortality rates than US-born Asians and Hispanics $(48,49)$. This paradox has also been observed with "overseas born" ethnic groups from other countries (50).

\section{Nutrition and Obesity}

In 2012, approximately one third of US children were classified as overweight or obese, as defined by BMI between 85th-94th percentiles, and $>95$ th percentile, respectively (51). Obesity is more prevalent among Hispanics (21.9\%) than NHW youth (14.7\%) (52), highlighting the need for further 
research on biological and sociocultural factors (53). Second and third generation immigrant Latino and Asian-American youth, compared with their first generation peers, in addition to those who are more acculturated, had higher prevalence of less healthy diets (less fruit, vegetables, and grains) and higher prevalence of obesity or overweight $(54,55)$. A plausible explanation for this observation is that children of immigrants, compared to their parents, may be raised in an environment with easier access to food and more sedentary behaviors, thus promoting obesity (56). Racial/ethnic minorities tend to have lower education levels and income, which can affect their comprehension of nutrition requirements and ability to purchase healthier and more expensive food (57).

Cultural values/status may also play a role. Some Latino parents consider that providing food for their children is an important aspect of good parenting (58-60), but this value can promote childhood obesity. A study among Latino women at risk for diabetes reported that improved economic conditions since immigration facilitated access to "high status foods" but, unfortunately, a less healthy diet as well (61). Lower acculturation (as measured by linguistic status) in Latino mothers was associated with increased BMI in their children (62). Among Asian-Americans, lower maternal acculturation increased the risk of elevated BMI in the child (63). It has been speculated that food insecurity (i.e., lack of access at all times to enough food for an active and healthy life) (64) in their native country may lead to unrestricted and thus, unhealthy eating patterns in the host country (65). Bilinguism in parents, which has been used as a marker for higher SES and/or acculturation, facilitates access to nutritional information and food resources, ultimately leading to healthier lifestyles for their child (66). Other studies have not found acculturation (as indicated by language use and generational status) related with probability of being overweight among Asian, Hispanic, and NHW adolescent females (67). Heterogeneity within Asian groups also needs to be considered; a study found that Korean-, Japanese-, and Filipino-American youth had greater obesogenic practices than South Asian- and Chinese-American youth (68).

The relationship between parenting styles and obesity may vary by ethnic group. The authoritative parenting style has high expectations for child behavior and high responsiveness to the child, while the authoritarian parent has high expectations for child behavior and low responsiveness to the child. Among US NHW families, authoritative parenting promotes healthy eating behaviors and BMI but, among racial/ethnic minorities, authoritarian parenting is associated with normal BMI, and high parental control protected against overweight and obesity. A potential explanation for this discrepancy is that the motivation for tight authoritarian parental control that tends to be practiced by Asian families may be concern for their children's well being, thus leading to healthy eating behaviors (69). However, in contrast, a pressure to eat due to parental control (70) may lead to overfeeding and obesity (71). Unfortunately, cultural issues with obesity and feeding practices are addressed less often than desirable during pediatrician visits (72).
FACTORS RELATED TO T1D EDUCATION, CARE, AND OUTCOMES IN LATINO AND ASIAN-AMERICAN YOUTH

\section{T1D in Latino and Asian-American Youth}

T1D is the most prevalent form of diabetes among Hispanicand Asian-American youth $(73,74)$. After adjusting for SES, Hispanic-American and Asian youth with T1D had significantly worse glycemic control than their NHW counterparts (75-78). Glycemic control was marginal to poor in 50\% of Hispanic children with T1D aged 0-9 y, and 65\% among patients $15 \mathrm{y}$ and older (74). Similarly, over $50 \%$ of AsianAmericans youth with T1D were in suboptimal glycemic control (73). No differences were found in frequency of diabetic ketoacidosis, hospitalizations, age at T1D diagnosis or mean insulin dose between Hispanic and NHW (75).

\section{Poverty, Healthcare Access, Health Literacy, and English Proficiency}

Barriers to diabetes care among youth with T1D are cost of care, poor access to care, and communication with health care providers $(79,80)$, which are interrelated with inadequate health insurance, low health literacy, English proficiency, and SES. SES, rather than race or ethnicity, was the major contributor to higher hemoglobin $\mathrm{Alc}(\mathrm{HbAlc})$ among Latino children (75). Both low SES and minority race/ethnicity were independent, negative predictors of continuous subcutaneous insulin infusion (insulin pump) use (81), which is associated with better glycemic control than other insulin delivery modalities (82). Greater material and social deprivation indices, but not race/ethnicity, were associated with worse $\mathrm{HbAlc}$ in children with T1D (83). Food insecurity predicted hospitalization in children with insulin-dependent diabetes (84). Poverty, nonWhite race, government insurance and young age were predictors of prolonged hospital stay in children with T1D (85). Poverty is a risk factor for readmission after T1D diagnosis (86).

Inadequate health insurance restricts access to quality care. Diabetic ketoacidosis, a life-threatening acute complication of T1D was more frequent in children without private health insurance (87). Frequency of self-monitoring of blood glucose, which is positively associated with diabetes control, was limited by certain insurers (88) and was lower among uninsured patients (89). Among uninsured children with T1D, cost of care is an important barrier to quality diabetes care (79). Children with T1D who are underinsured were more likely to require hospital admission after the diagnosis (90).

Language can be a barrier to quality health care $(91,92)$ but native language materials alone did not produce adequate health literacy among parents' caregivers (93). Besides foreign language educational materials, emotional support, understanding of family dynamics and cultural values are necessary for effective culturally sensitive diabetes care in youth. Among English and Spanish speaking adults with T2D, low health literacy was a barrier to tight glycemic control (HbAlc $<7.2 \%$ ) (94). Among adolescents with T1D, parent health literacy (specifically, reading comprehension) was positively associated with adolescents' adherence to intensive insulin regimens (95). 


\section{Review | Gandhiet al.}

In addition, reading skills and, in particular, numeracy among parent caregivers improved HbAlc among their children with T1D $(96,97)$. Paradoxically, among Hispanic adults with diabetes, low health literacy was linked to greater physician trust, treatment adherence, and self-efficacy in their diabetes care, which can improve glycemic control $(98,99)$.

Chinese-American adults with T2D and lower English language proficiency were less able to complete daily diabetes tasks due to limited communication with their health care provider (100). Receiving nutritional information and emotional support in their native language improved their daily diabetes management and a bilingual Chinese health care provider who was both an expert in the medical field and emotionally caring was preferred (100). Language barriers were also noted among South Asian adults with T2D (101).

Vietnamese adolescents' ability to speak their native language enhanced communication with their families and improved family functioning (102). Hispanic youth with T1D reported more problems with communication and contextual care (consideration of daily family and child circumstances) compared with NHW youth (79). Unfortunately, few qualitative T1D pediatric studies address cultural issues in providerpatient communication.

\section{Acculturation, Family Functioning, and Mental Health}

Among Hispanic youth, blood glucose monitoring was performed with less frequency but with more parental supervision compared to NHW youth (75). Less acculturated (measured by recent generational status) Hispanic adolescent T1D youth participated less in their own diabetes care but their strong family support facilitated adherence to diabetes-related responsibilities, ultimately achieving better glycemic control than other groups (103). Conversely, Hispanic-American youth with more independent responsibility and less family support for their diabetes management appeared to be less adherent (103). It could be speculated that the Hispanic value of "familismo" may promote family involvement, or a sense of obligation toward authority (in this case, health providers), improving adherence to diabetes management (103). However, "familismo" may also cause delays in medical decision making, as family must be consulted first (104). Importantly, although family involvement in diabetes care is important for glycemic control $(105,106)$, the benefit of encouraging adolescent autonomy and independence during transition to diabetes self-care has also been demonstrated $(103,107)$.

Authoritative parental involvement and more communication were related to better adherence and improved $\mathrm{HbAlc}$ among youth with T1D $(108,109)$. Since this is not the parenting style that has been traditionally associated with Asian families (110), more research is needed to understand how acculturation influences T1D adherence and glycemic control in Asian-American youth. Irrespective of ethnicity, psychosocial factors profoundly affect diabetes care in people with T1D. Parental involvement in blood glucose monitoring and insulin administration led to increased frequency of blood glucose monitoring, which significantly enhanced glycemic control among youths with T1D $(105,106)$. Youth from families in which feelings were expressed openly, communicated more on diabetes management, had lower levels of family conflict and greater coordination among all family members (not just parents), achieved better metabolic control $(109,111)$. Adolescents with discordance between autonomy for their diabetes care and their maturity level to manage these independently developed problems in daily diabetes management and experienced increased risk of adverse events (112). Immigrant families and youth possessed diverse levels of "social competence" (i.e., competence in school and peer relations) $(113,114)$. Low social competence was associated with poor diabetes adherence among adolescents with T1D (115). Generally, psychosocial factors and family dynamics become established soon after diagnosis, but follow a deteriorating trajectory (116). Thus, establishing optimal family routines and social skills for diabetes care is vitally important early in the disease course.

Depression and low quality of life in youth with T1D adversely affect glycemic control (117). The Hispanic/Latino and Asian youth population experience higher rates of depressive symptoms than other racial/ethnic groups (118-120). Latinos, who tended to have more family support, revealed lower utilization of professional mental health services, perhaps due to the constructive support they receive, or due to the fear of family stigmatization (121). Several Latino cultural values influence the risk of depression, often in contradictory fashion. Referent and support "familismo" may protect against depressive symptoms (122) but obligation "familismo" is associated with increased depression among adults, although not in adolescents (122). Perhaps the later have not yet assumed possibly overwhelming family obligations that could contribute to depression (122). Symptoms of depression increased with acculturation (123), possibly due to impaired family functioning or deviation from protective Latino cultural values of family unity and decreased conflict $(123,124)$. "Fatalismo" (i.e., the belief that there is little individual control over life's negative events) was related to higher family conflict, which may contribute to internal conflict and depression among Hispanic youth (30).

Traditional Latino gender roles also affect mental health and thus diabetes outcomes. "Machismo" can have detrimental effects (e.g., dominance over family affairs and spouse) and positive effects (e.g., males exhibit independence, protect the family, and promote seeking health services) $(104,125)$. Among Mexican-American adolescents, traditional gender roles can protect females, but predispose males to risky behavior (29). Similarly, traditional gender values may modulate mental health behavior, and family roles in adherence to therapy $(29,125)$.

In contrast to Latinos, less acculturated Asians had higher rates of stress and emotional distress (126), under-utilized mental health services (121) and were more likely to be uninsured compared to NHW $(34,127)$. Among Asian adolescents, the degree of intergenerational discrepancy (which can cause family conflict) predicted depressive symptoms (128). Less acculturated Asian-American youth experienced a greater 
risk for depression and suicide when faced with family conflict, possibly due to distress over traditional values of humility and parental control (128). Acculturation also changes parental roles that may disrupt familial harmony and cohesiveness, affecting rates of depression. A study showed that AsianAmerican parents tended to employ authoritarian parenting (110), which may lower self-esteem and increase depression risk $(129,130)$. Authoritative parenting style was associated with lower adolescent depression scores, and higher adolescent self-efficacy and self-esteem than the authoritarian parenting style (131).

\section{Nutrition and Obesity}

The rate of overweight and obesity has tripled since the 1980s among children and adolescents with T1D, and is now over $34 \%$ $(132,133)$, being the highest among Hispanic- and AfricanAmerican youth $(132,134)$. Up to $44 \%$ of Hispanic-American youth with T1D and over 30\% of Asian-American youth with T1D aged $0-19$ y were overweight or obese $(73,74)$. Obesity negatively affects T1D outcomes as it increases the risk of poor glycemic control (78), cardiovascular disease, and micro-vascular complications, possibly through insulin resistance and higher levels of inflammatory adipokines and cytokines (135). In addition, obesity may precipitate the clinical onset of T1D (136) through lower insulin sensitivity as suggested by the finding of greater beta cell function at diagnosis (137). Insulin sensitivity was lower among Hispanic youth without (138) and with (139) T1D compared to their NHW counterparts, although contradictory studies exist (140). Dyslipidemia, another cardiovascular risk factor, also associated with diet and obesity, was prevalent in Hispanic adolescents aged 15-19 $\mathrm{y}$ with T1D, with hypertriglyceridemia; and elevated LDL cholesterol levels in $30 \%$ and $48 \%$ of them, respectively (74).

\section{CURRENT CLINICAL INITIATIVES}

Culturally sensitive clinical programs take into consideration a racial/ethnic group's traditions, values, and practices while maintaining the quality of education and care provided. Cultural competence of a health care institution to interact with patients from another culture involves improvement at various levels: organizational (more diverse leadership), structural (availability of translators), and clinical (more cultural competence among health care providers) (141). Unfortunately, these culturally competent initiatives are scarce for Latino or AsianAmerican youth with T1D. A small study showed improvement in HbAlc in Hispanic T1D youth at a "Spanish-only" clinic (142).

Culturally sensitive health interventions to improve T2D care and outcomes among the Latino and Asian adult populations have been tried, and shown to be effective, improving diabetes knowledge, self-efficacy, and glycemic control, while reducing the incidence of diabetic complications and controlling medical costs $(143,144)$. Culturally sensitive diabetes interventions for Latinos and Asian Americans included bilingual educators, educational materials, and culturally identifiable focus groups $(143,144)$. One study called "Every Little Step Counts: Diabetes
Prevention Program" utilized "promotoras" (i.e., community members trained in basic health education) to improve physical activity and weight status among high-risk Latino youths (145). More culturally sensitive interventions targeting Latino and Asian-American youth are needed.

It is unclear what characteristics make an effective intervention culturally sensitive. "Vida Saludable," a 9-mo behavioral program targeted at Hispanic mothers to promote healthy behaviors for their children, improved children's consumption of water and milk, reduced consumption of sugar sweetened beverages, reduced maternal BMI, and showed satisfaction with "promotora" support during the intervention, indicating the power of maternal influence on their children's healthy behaviors (146). However, "Hip Hop to Health," a culturally sensitive obesity prevention intervention targeting Latinos, was not successful (147) possibly due to insufficient parent involvement, consistent with previous studies demonstrating that level of physical activity correlates between parents and children (148). Most recently, an intervention named "SaludABLEOmaha" was applied to childhood obesity in the Latino community. This program included youth activism, community engagement through social media and marketing, and content based curricula, and was able to increase the readiness level of this community to improve childhood obesity. "Community readiness" is a stage at which a community (including a cultural group) is willing to address a health issue (149).

The White House Task Force on Childhood Obesity outlined interventions for targeting childhood obesity through the "Let's Move" campaign, which involves local and faith-based health initiatives for obesity (150). This program is largely based on the observation that early life risk factors, such as solid food introduction before $4 \mathrm{mo}$ of age, sweetened beverage intake at $2 \mathrm{y}$ of age, and fast food intake, are more prevalent among Hispanic than NHW children (151). The Racial and Ethnic Approaches to Community Health program, through the CDC National Center for Chronic Disease Prevention and Health Promotion, aids in carrying out culturally sensitive health programs with local agencies in various health care fields including T2D (152).

Diabetes initiatives targeting Latinos and Asian-Americans include the Joslin Diabetes Center's Latino Diabetes Initiative (153) and Asian-American Diabetes Initiative (AADI) which currently focuses on Chinese and Japanese Americans (154). Asian-American Diabetes Initiative's goals are to study diabetes in the Asian-American population and disseminate their research findings to provide culturally sensitive diabetes education, outreach programs, develop treatment strategies, and provide awareness to issues in diabetes relevant to AsianAmericans. This multidisciplinary initiative consists of physicians and dieticians who lead the Asian-American Diabetes clinic and provide culturally sensitive online tools for diabetes and nutrition care (154).

Current initiatives are also limited by the heterogeneity of Latino and Asian- American populations regarding essential characteristics such as SES. Future qualitative and quantitative 
research on acculturation should differentiate heterogeneous Latino and Asian-American groups, adapt established acculturation measures within specific cultural populations, account for SES and other potential confounders, and comprehensively identify specific risk behaviors that affect diabetes care and adherence. The large and increasing number of Latino and Asian-American families in the United States underscores the significance of research on strategies to best address their health needs to reduce disparities.

\section{CONCLUSION}

Latino and Asian-Americans represent the fastest growing immigrant populations in the United States. Most Latino and AsianAmerican youth with T1D are in suboptimal diabetes control and therefore at high risk for the devastating acute and chronic complications of T1D. SES, access to health care, health literacy, English proficiency, acculturation, family functioning, mental health, and nutrition are intimately inter-related, have a complex effect on T1D and are largely understudied in these populations. Better understanding of the factors that influence T1D education, care, and outcomes will shed light on how to best accommodate the needs of these growing groups within the existing health system in the United States. Specific, clinical programs for Latino and Asian-American youth with T1D that take into consideration the racial/ethnic group's traditions, values, and practices while maintaining the quality of education are warranted to address health disparities. Research is needed among Latino and Asian-American youth with T1D, so that comprehensive, culturally sensitive diabetes education and care programs can be developed to decrease disparities in the health burden of these groups.

\section{ACKNOWLEDGMENTS}

The authors thank Dr B. Lee Ligon of the Center for Research, Innovation and Scholarship, Department of Pediatrics, Baylor College of Medicine, for editorial assistance.

\section{STATEMENT OF FINANCIAL SUPPORT}

This research article was made possible in part by institutional support to Dr Tom Baranowski from the US Department of Agriculture, Agricultural Research Service (Cooperative Agreement 58-6250-0-008).

Disclosure: The authors have no financial ties to products in the study or potential/perceived conflicts of interest.

\section{REFERENCES}

1. United States Census Bureau, United States Department of Commerce. How Do We Know? America's Foreign Born in the Last 50 Years, 2015. (http://www.census.gov/library/infographics/foreign_born.html.)

2. Hayes-Bautista DE, Chapa J. Latino terminology: conceptual bases for standardized terminology. Am J Public Health 1987;77:61-8.

3. United States Census Bureau, United States Department of Commerce, 2010 Census Briefs. The Hispanic Population: 2010, 2015. (http://www. census.gov/prod/cen2010/briefs/c2010br-04.pdf.).

4. United States Census Bureau, United States Department of Commerce, 2014 Fact Finder: Hispanic or Latino by Origin, 2015. (http://factfinder. census.gov/faces/tableservices/jsf/pages/productview.xhtml?src=bkmk.).

5. United States Census Bureau, United States Department of Commerce, 2010 Census Briefs. The Asian Population: 2010, 2015. (https://www.census.gov/prod/cen2010/briefs/c2010br-11.pdf.).

6. Forum on Child and Family Statistics. America's Children: Key National Indicators of Well-Being, 2015. (http://www.childstats.gov/pdf/ac2015/ ac_15.pdf. ) .
7. Federal interagency Forum on Child and Family Statistics. Children of at least one foreign-born parent: Percentage of children ages $0-17$ by nativity of child and parents, parent's education, poverty status, and other characteristics, selected years 1994-2014, 2015. (http://www.childstats.gov/ americaschildren/tables.asp). .

8. United States Census Bureau, United States Department of Commerce. Income and Poverty in the United States: Current Population Reports: 2014, 2015. (http://www.census.gov/content/dam/Census/library/publications/2015/demo/p60-252.pdf.).

9. Pew Research Center: Hispanic Trends. Childhood Poverty Among Hispanics Sets Record, Leads Records, 2015. (http://www.pewhispanic.org/2011/09/28/ childhood-poverty-among-hispanics-sets-record-leads-nation/.).

10. Berry JW. Immigraton, acculturation, and adaptation. Appl Pyschol: An Int Rev 1997;46:5-34.

11. Schwartz SJ, Unger JB, Zamboanga BL, Szapocznik J. Rethinking the concept of acculturation: implications for theory and research. Am Psychol 2010;65:237-51.

12. Schwartz SJ, Montgomery M, Briones E. The role of identity in acculturation among immigrant people: Theoretical propositions, empirical questions, and applied recommendations. Hum Dev 2006;49:1-30.

13. Cordova D, Ciofu A, Cervantes R. Exploring culturally based intrafamilial stressors among Latino adolescents. Fam Relat 2014;63:693-706.

14. Unger JB, Ritt-Olson A, Soto DW, Baezconde-Garbanati L. Parent-child acculturation discrepancies as a risk factor for substance use among Hispanic adolescents in Southern California. J Immigr Minor Health 2009;11:149-57.

15. Lowinger RJ, Kwok, H. Parental overprotection in Asian American children: a psychodynamic perspective. Psychotherapy 2001;38:319-30.

16. Varghese A, Jenkins SR. Parental overprotection, cultural value conflict, and psychological adaptation among Asian Indian women in America. Sex Roles 2009;61:235-51.

17. Lui PP, Rollock D. Tiger mother: popular and psychological scientific perspectives on Asian culture and parenting. Am J Orthopsychiatr. 2013;83:450-6.

18. Bámaca-Colbert MY, Gayles JG. Variable-centered and person-centered approaches to studying Mexican-origin mother-daughter cultural orientation dissonance. J Youth Adolesc 2010;39:1274-92.

19. Juang LP, Syed M, Takagi M. Intergenerational discrepancies of parental control among Chinese American families: links to family conflict and adolescent depressive symptoms. J Adolesc 2007;30:965-75.

20. Galobardes B, Lynch JW, Smith GD. Is the association between childhood socioeconomic circumstances and cause-specific mortality established? Update of a systematic review. J Epidemiol Community Health 2008;62:387-90.

21. Cheng TL, Goodman E; Committee on Pediatric Research. Race, ethnicity, and socioeconomic status in research on child health. Pediatr 2015; 135:e225-37.

22. United States Census Bureau, United States Department of Commerce. American Community Survey Reports: The Foreign-Born Population in the United States: 2010, 2015. (http://www.census.gov/content/dam/Census/library/publications/2012/acs/acs-19.pdf.).

23. Negy C, Woods, D. A note on the relationship between acculturation and socioeconomic status. Hisp J Behav Sci 1992;14:248-51.

24. Williams DR, Collins C. Racial residential segregation: a fundamental cause of racial disparities in health. Public Health Rep 2001;116:404-16.

25. Terzano K. Commodification of transitioning ethnic enclaves. Behav Sci (Basel) 2014;4:341-51.

26. Marin G, Marin, BV. Research with Hispanic Populations. Newbury Park: Sage Publications; 1991.

27. Fuligni A, Tseng, V, Lam, M. Attitudes toward family obligations among American adolescents with Asian, Latin American, and European backgrounds. Child Dev 1999;70:1030-44.

28. Sabogal F, Marin G., Otero-Sabogal R. Hispanic familism and acculturation: what changes and what doesn't? Hisp J of Behav Sci 1987;9:397-412.

29. Updegraff KA, Umaña-Taylor AJ, McHale SM, Wheeler LA, PerezBrena NJ. Mexican-origin youth's cultural orientations and adjustment: changes from early to late adolescence. Child Dev 2012;83:1655-71. 
30. Lorenzo-Blanco EI, Unger JB, Baezconde-Garbanati L, Ritt-Olson A, Soto D. Acculturation, enculturation, and symptoms of depression in Hispanic youth: the roles of gender, Hispanic cultural values, and family functioning. J Youth Adolesc 2012;41:1350-65.

31. Lin $\mathrm{C}, \mathrm{Fu}, \mathrm{V}$. A Comparison of child-rearing practices among chinese, immigrant chinese, and Caucasian-American parents. Child Dev 1990;61:429-33.

32. Phinney JS, Ong A, Madden T. Cultural values and intergenerational value discrepancies in immigrant and non-immigrant families. Child Dev 2000;71:528-39.

33. Evans GW. The environment of childhood poverty. Am Psychol 2004;59:77-92.

34. United States Census Bureau, United States Department of Commerce, Health Insurance Coverage in the United States: 2014, 2015. (http://www.census.gov/content/dam/Census/library/publications/2015/demo/p60-253.pdf).

35. Centers for Disease Control. Summary Health Statistics for U.S. Children: National Health Interview Survey: Selected Measures of Health Care Access for Children Under Age 18 Years, 2014, 2015. (http://ftp.cdc.gov/ pub/Health_Statistics/NCHS/NHIS/SHS/2014_SHS_Table_C-9.pdf).

36. Centers for Disease Control. Summary Health Statistics for U.S. Children: National Health Interview Survey: Having a Usual Place of Health Care, and Age-adjusted Percent Distributions of Type of Place, for Children Under Age 18 Years, 2014, 2015. (http://ftp.cdc.gov/pub/Health_Statistics/ NCHS/NHIS/SHS/2014_SHS_Table_C-7.pdf).

37. Chang E, Chan KS, Han HR. Effect of acculturation on variations in having a usual source of care among Asian Americans and non-Hispanic whites in California. Am J Public Health 2015;105:398-407.

38. Agency of Healthcare Research and Quality, Department of Health and Human Services. National Healthcare Disparities Report: Chapter 9. Access to Health Care, 2015. (http://archive.ahrq.gov/research/findings/ nhqrdr/nhdr12/chap9.html. ).

39. Wen XJ, Balluz L. Racial disparities in access to health care and preventive services between Asian Americans/Pacific islanders and non-Hispanic Whites. Ethn Dis 2010;20:290-5.

40. Migration Policy Institute. The Limited English Proficient Population in the United States, 2015. (http://www.migrationpolicy.org/article/limitedenglish-proficient-population-united-states.).

41. Sentell T, Braun KL. Low health literacy, limited English proficiency, and health status in Asians, Latinos, and other racial/ethnic groups in California. J Health Commun 2012;17 Suppl 3:82-99.

42. DeWalt DA, Hink A. Health literacy and child health outcomes: a systematic review of the literature. Pediatr 2009;124 Suppl 3:S265-74.

43. Office of Disease Prevention and Health Promotion Health Communication Activities, U.S. Department of Health and Human Services. America’s Health Literacy: Why We Need Accessible Health Information, 2015. (http://health.gov/communication/literacy/issuebrief/.).

44. Abraído-Lanza AF, Chao MT, Flórez KR. Do healthy behaviors decline with greater acculturation? Implications for the Latino mortality paradox. Soc Sci Med 2005;61:1243-55.

45. Ruiz JM, Steffen P, Smith TB. Hispanic mortality paradox: a systematic review and meta-analysis of the longitudinal literature. Am J Public Health 2013;103:e52-60.

46. Pablos-Méndez A. Mortality among Hispanics. JAMA 1994;271:1237.

47. Abraído-Lanza AF, Dohrenwend BP, Ng-Mak DS, Turner JB. The Latino mortality paradox: a test of the "salmon bias" and healthy migrant hypotheses. Am J Public Health 1999;89:1543-8.

48. Singh GK, Siahpush M. Ethnic-immigrant differentials in health behaviors, morbidity, and cause-specific mortality in the United States: an analysis of two national data bases. Hum Biol 2002;74:83-109.

49. Goggins WB, Wong G. Cancer among Asian Indians/Pakistanis living in the United States: low incidence and generally above average survival. Cancer Causes Control 2009;20:635-43.

50. Jatrana S, Richardson K, Blakely T, Dayal S. Does mortality vary between Asian subgroups in New Zealand: an application of hierarchical Bayesian modelling. PLoS One 2014;9:e105141.

51. Ogden CL, Carroll MD, Kit BK, Flegal KM. Prevalence of childhood and adult obesity in the United States, 2011-2012. JAMA 2014;311:806-14.
52. Ogden CL, Carroll MD, Fryar CD, Flegal KM. Prevalence of obesity among adults and youth: United States, 2011-2014. NCHS data brief, no 219. Hyattsville, MD: National Center for Health Statistics. 2015.

53. Gordon-Larsen P, Harris KM, Ward DS, Popkin BM; National Longitudinal Study of Adolescent Health. Acculturation and overweight-related behaviors among Hispanic immigrants to the US: the National Longitudinal Study of Adolescent Health. Soc Sci Med 2003;57:2023-34.

54. Liu JH, Chu YH, Frongillo EA, Probst JC. Generation and acculturation status are associated with dietary intake and body weight in Mexican American adolescents. J Nutr 2012;142:298-305.

55. Popkin BM, Udry JR. Adolescent obesity increases significantly in second and third generation U.S. immigrants: the National Longitudinal Study of Adolescent Health. J Nutr 1998;128:701-6.

56. Morland K, Wing S, Diez Roux A, Poole C. Neighborhood characteristics associated with the location of food stores and food service places. Am J Prev Med 2002;22:23-9.

57. Jetter KM, Cassady DL. The availability and cost of healthier food alternatives. Am J Prev Med 2006;30:38-44.

58. Sussner KM, Lindsay AC, Greaney ML, Peterson KE. The influence of immigrant status and acculturation on the development of overweight in Latino families: a qualitative study. J Immigr Minor Health 2008;10: 497-505.

59. Higgins B. Puerto Rican cultural beliefs: influence on infant feeding practices in western New York. J Transcult Nurs 2000;11:19-30.

60. Bunik M, Clark L, Zimmer LM, et al. Early infant feeding decisions in lowincome Latinas. Breastfeed Med 2006;1:225-35.

61. O'Brien MJ, Shuman SJ, Barrios DM, Alos VA, Whitaker RC. A qualitative study of acculturation and diabetes risk among urban immigrant Latinas: implications for diabetes prevention efforts. Diabetes Educ 2014;40: 616-25.

62. Sussner KM, Lindsay AC, Peterson KE. The influence of maternal acculturation on child body mass index at age 24 months. J Am Diet Assoc 2009;109:218-25.

63. Chen JL, Weiss S, Heyman MB, Lustig R. Risk factors for obesity and high blood pressure in Chinese American children: maternal acculturation and children's food choices. J Immigr Minor Health 2011;13:268-75.

64. United States Department of Agriculture, Economic Research Service, Food Insecurity in the U.S., 2015. (http://www.ers.usda.gov/topics/foodnutrition-assistance/food-security-in-the-us.aspx).

65. Cheah CS, Van Hook J. Chinese and Korean immigrants' early life deprivation: an important factor for child feeding practices and children's body weight in the United States. Soc Sci Med 2012;74:744-52.

66. Dubowitz T, Smith-Warner SA, Acevedo-Garcia D, Subramanian SV, Peterson KE. Nativity and duration of time in the United States: differences in fruit and vegetable intake among low-income postpartum women. Am J Public Health 2007;97:1787-90.

67. Fialkowski MK, Ettienne R, Shvetsov YB, et al. Ethnicity and acculturation: do they predict weight status in a longitudinal study among Asian, Hispanic, and non-Hispanic White early adolescent females? Adolesc Health Med Ther 2015;6:1-7.

68. Guerrero AD, Ponce NA, Chung PJ. Obesogenic dietary practices of Latino and Asian subgroups of children in California: an analysis of the California health interview survey, 2007-2012. Am J Public Health 2015;105: e105-12.

69. Chen JL, Kennedy, C. Family functioning, parenting Style, and chinese children's weight status. J Fam Nurs 2004;10:262-79.

70. Momin SR, Chung KR, Olson BH. A qualitative study to understand positive and negative child feeding behaviors of immigrant Asian Indian mothers in the US. Matern Child Health J 2014;18:1699-710.

71. Carper JL, Orlet Fisher J, Birch LL. Young girls' emerging dietary restraint and disinhibition are related to parental control in child feeding. Appetite 2000;35:121-9.

72. Turer CB, Montaño S, Lin H, Hoang K, Flores G. Pediatricians' communication about weight with overweight Latino children and their parents. Pediatr 2014;134:892-9.

73. Liu LL, Yi JP, Beyer J, et al.; SEARCH for Diabetes in Youth Study Group. Type 1 and Type 2 diabetes in Asian and Pacific Islander U.S. youth: the 
SEARCH for diabetes in youth study. Diabetes Care 2009;32 Suppl 2: S133-40.

74. Lawrence JM, Mayer-Davis EJ, Reynolds K, et al.; SEARCH for Diabetes in Youth Study Group. Diabetes in Hispanic American youth: prevalence, incidence, demographics, and clinical characteristics: the SEARCH for diabetes in youth study. Diabetes Care 2009;32 Suppl 2:S123-32.

75. Gallegos-Macias AR, Macias SR, Kaufman E, Skipper B, Kalishman N. Relationship between glycemic control, ethnicity and socioeconomic status in Hispanic and white non-Hispanic youths with type 1 diabetes mellitus. Pediatr Diabetes 2003;4:19-23.

76. Jacobsen JJ, Black MH, Li BH, Reynolds K, Lawrence JM. Race/ethnicity and measures of glycaemia in the year after diagnosis among youth with type 1 and type 2 diabetes mellitus. J Diabetes Complications 2014;28: $279-85$.

77. Willi SM, Miller KM, DiMeglio LA, et al.; T1D Exchange Clinic Network. Racial-ethnic disparities in management and outcomes among children with type 1 diabetes. Pediatr 2015;135:424-34.

78. Petitti DB, Klingensmith GJ, Bell RA, et al.; SEARCH for Diabetes in Youth Study Group. Glycemic control in youth with diabetes: the SEARCH for diabetes in youth study. J Pediatr 2009;155(5):668-72.e1-3.

79. Valenzuela JM, Seid M, Waitzfelder B, et al.; SEARCH for Diabetes in Youth Study Group. Prevalence of and disparities in barriers to care experienced by youth with type 1 diabetes. J Pediatr 2014;164:1369-75.e1.

80. Naranjo D, Schwartz DD, Delamater AM. Diabetes in ethnically diverse youth: disparate burden and intervention approaches. Curr Diabetes Rev 2015;11:251-60.

81. Lin MH, Connor CG, Ruedy KJ, et al.; Pediatric Diabetes Consortium. Race, socioeconomic status, and treatment center are associated with insulin pump therapy in youth in the first year following diagnosis of type 1 diabetes. Diabetes Technol Ther 2013;15:929-34.

82. Pihoker C, Badaru A, Anderson A, et al.; SEARCH for Diabetes in Youth Study Group. Insulin regimens and clinical outcomes in a type 1 diabetes cohort: the SEARCH for diabetes in youth study. Diabetes Care 2013;36:27-33.

83. Zuijdwijk CS, Cuerden M, Mahmud FH. Social determinants of health on glycemic control in pediatric type 1 diabetes. J Pediatr 2013;162:730-5.

84. Marjerrison S, Cummings EA, Glanville NT, Kirk SF, Ledwell M. Prevalance and associations of food insecurity in children with diabetes mellitus. J Pediatr 2011;158:607-11.

85. Keenan HT, Foster CM, Bratton SL. Social factors associated with prolonged hospitalization among diabetic children. Pediatr 2002;109:40-4.

86. Fishbein HA, Faich GA, Ellis SE. Incidence and hospitalization patterns of insulin-dependent diabetes mellitus. Diabetes Care 1982;5:630-3.

87. Klingensmith GJ, Tamborlane WV, Wood J, et al.; Pediatric Diabetes Consortium. Diabetic ketoacidosis at diabetes onset: still an all too common threat in youth. J Pediatr 2013;162:330-4.e1.

88. Miller KM, Beck RW, Bergenstal RM, et al.; T1D Exchange Clinic Network. Evidence of a strong association between frequency of self-monitoring of blood glucose and hemoglobin A1c levels in T1D exchange clinic registry participants. Diabetes Care 2013;36:2009-14.

89. Yi-Frazier JP, Hood K, Case D, et al.; SEARCH for Diabetes in Youth Study Group. Caregiver reports of provider recommended frequency of blood glucose monitoring and actual testing frequency for youth with type 1 diabetes. Diabetes Res Clin Pract 2012;95:68-75.

90. Estrada CL, Danielson KK, Drum ML, Lipton RB. Hospitalization subsequent to diagnosis in young patients with diabetes in Chicago, Illinois. Pediatr 2009;124:926-34.

91. Andrulis DP, Brach C. Integrating literacy, culture, and language to improve health care quality for diverse populations. Am J Health Behav 2007;31 Suppl 1:S122-33.

92. Jaacks LM, Oza-Frank R, D’Agostino R Jr, et al. Migration status in relation to clinical characteristics and barriers to care among youth with diabetes in the US. J Immigr Minor Health 2012;14:949-58.

93. Leyva M, Sharif I, Ozuah PO. Health literacy among Spanish-speaking Latino parents with limited English proficiency. Ambul Pediatr 2005;5: 56-9.
94. Schillinger D, Grumbach K, Piette J, et al. Association of health literacy with diabetes outcomes. JAMA 2002;288:475-82.

95. Janisse HC, Naar-King S, Ellis D. Brief report: Parent's health literacy among high-risk adolescents with insulin dependent diabetes. J Pediatr Psychol 2010;35:436-40.

96. Hassan K, Heptulla RA. Glycemic control in pediatric type 1 diabetes: role of caregiver literacy. Pediatr 2010;125:e1104-8.

97. Pulgarón ER, Sanders LM, Patiño-Fernandez AM, et al. Glycemic control in young children with diabetes: the role of parental health literacy. Patient Educ Couns 2014;94:67-70.

98. White RO, Osborn CY, Gebretsadik T, Kripalani S, Rothman RL. Health literacy, physician trust, and diabetes-related self-care activities in Hispanics with limited resources. J Health Care Poor Underserved 2013;24:175668.

99. Osborn CY, Cavanaugh K, Wallston KA, Rothman RL. Self-efficacy links health literacy and numeracy to glycemic control. J Health Commun 2010;15 Suppl 2:146-58.

100. Chun KM, Chesla CA, Kwan CM. "So We Adapt Step by Step": Acculturation experiences affecting diabetes management and perceived health for Chinese American immigrants. Soc Sci Med 2011;72:256-64.

101. Sohal T, Sohal P, King-Shier KM, Khan NA. Barriers and Facilitators for Type-2 Diabetes Management in South Asians: A Systematic Review. PLoS One 2015;10:e0136202.

102. Ho J, Birman D. Acculturation gaps in Vietnamese immigrant families: Impact on family relationships. Int J Intercult Relat 2010;34:22-3.

103. Hsin O, La Greca AM, Valenzuela J, Moine CT, Delamater A. Adherence and glycemic control among Hispanic youth with type 1 diabetes: role of family involvement and acculturation. J Pediatr Psychol 2010;35:156-66.

104. Caballero AE. Understanding the Hispanic/Latino patient. Am J Med 2011;124(10 Suppl):S10-5.

105. Levine BS, Anderson BJ, Butler DA, Antisdel JE, Brackett J, Laffel LM. Predictors of glycemic control and short-term adverse outcomes in youth with type 1 diabetes. J Pediatr 2001;139:197-203.

106. Anderson B, Ho J, Brackett J, Finkelstein D, Laffel L. Parental involvement in diabetes management tasks: relationships to blood glucose monitoring adherence and metabolic control in young adolescents with insulin-dependent diabetes mellitus. J Pediatr 1997;130:257-65.

107. Roche KM, Caughy MO, Schuster MA, Bogart LM, Dittus PJ, Franzini L. Cultural orientations, parental beliefs and practices, and latino adolescents' autonomy and independence. J Youth Adolesc 2014;43:1389-403.

108. Davis CL, Delamater AM, Shaw KH, et al. Parenting styles, regimen adherence, and glycemic control in 4- to 10 -year-old children with diabetes. J Pediatr Psychol 2001;26:123-9.

109. Hanna KM, Juarez B, Lenss SS, Guthrie D. Parent-adolescent communication and support for diabetes management as reported by adolescents with type 1 diabetes. Issues Compr Pediatr Nurs 2003;26:145-58.

110. Chiu HL. Child rearing attitudes of Chinese, Chinese-American, and Anglo-American mothers. Int J Psychol 1987;22:409-19.

111. Anderson BJ, Vangsness L, Connell A, Butler D, Goebel-Fabbri A, Laffel LM. Family conflict, adherence, and glycaemic control in youth with short duration Type 1 diabetes. Diabet Med 2002;19:635-42.

112. Wysocki T, Taylor A, Hough BS, Linscheid TR, Yeates KO, Naglieri JA. Deviation from developmentally appropriate self-care autonomy. Association with diabetes outcomes. Diabetes Care 1996;19:119-25.

113. Kim E, Han G, McCubbin MA. Korean American maternal acceptancerejection, acculturation, and children's social competence. Fam Community Health 2007;30(2 Suppl):S33-45.

114. Prelow H, Loukas, A, Jordan-Green, L. Socioenvironmental risk and adjustment in Latino youth: The mediating effects of family processes and social competence. J Youth and Adolesc 2007;36:465-76.

115. Hanson CL, Henggeler SW, Burghen GA. Model of associations between psychosocial variables and health-outcome measures of adolescents with IDDM. Diabetes Care 1987;10:752-8.

116. Grey M, Cameron ME, Lipman TH, Thurber FW. Psychosocial status of children with diabetes in the first 2 years after diagnosis. Diabetes Care 1995;18:1330-6. 
117. Hood KK, Beavers DP, Yi-Frazier J, et al. Psychosocial burden and glycemic control during the first 6 years of diabetes: results from the SEARCH for diabetes in youth study. J Adolesc Health 2014;55:498-504.

118. Choi H, Meininger JC, Roberts RE. Ethnic differences in adolescents' mental distress, social stress, and resources. Adolesc 2006;41:263-83.

119. Saluja G, Iachan R, Scheidt PC, Overpeck MD, Sun W, Giedd JN. Prevalence of and risk factors for depressive symptoms among young adolescents. Arch Pediatr Adolesc Med 2004;158:760-5.

120. Greenberger EC, Chen C. Perceived family relationships and depressed mood in early and late adolescence: a comparison of European and Asian Americans. Dev Psychol 1996;32:707-16.

121. Snowden LR. Explaining mental health treatment disparities: ethnic and cultural differences in family involvement. Cult Med Psychiatr 2007;31:389-402.

122.Zeiders KH, Updegraff KA, Umaña-Taylor AJ, Wheeler LA, PerezBrena NJ, Rodríguez SA. Mexican-origin youths' trajectories of depressive symptoms: the role of familism values. J Adolesc Health 2013;53:648-54.

123. Gonzales NA, Deardoff, J, Formoso, D, Barr, A, Barrera Jr, M. Family mediators of the relation between acculturation and adolescent mental health. Family Relations 2006;55:318-30.

124. Miranda AO, Estrada, D, Firpo-Jimenez, M. Differences in family cohesion, adaptability, and environment among Latino families in dissimilar stages of acculturation. The Family J: Counsel and Therapy for Couples and Families 2000;8:341-50.

125. Cuellar IA, Amold B, Genaro G. Cognitive referents of acculturation:assessment of cultural constructs in Mexican Americans. J Commun Psychol 1995;23:339-56.

126. Hilario CT, Vo DX, Johnson JL, Saewyc EM. Acculturation, gender, and mental health of Southeast Asian immigrant youth in Canada. J Immigr Minor Health 2014;16:1121-9.

127. Agency of Healthcare Research and Quality, Department of Health and Human Services. National Healthcare Disparities Report: Chapter 10. Priority Populations, 2015. (http://www.ahrq.gov/research/findings/nhqrdr/ nhdr12/chap10.html - Minorities).

128. Lau AS, Jernewall NM, Zane N, Myers HF. Correlates of suicidal behaviors among Asian American outpatient youths. Cultur Divers Ethnic Minor Psychol 2002;8:199-213.

129. Herz L, Gullone, E. The relationship between self-esteem and parenting style: a cross cultural comparison of Australian and Vietnamese Australian adolescents. J Cross-Cul Psychol 1999;30:742-61.

130. Nguyen PV. Perceptions of Vietnamese fathers' acculturation levels, parenting styles, and mental health outcomes in Vietnamese American adolescent immigrants. Soc Work 2008;53:337-46.

131. Steinberg L, Morris AS. Adolescent development. Annu Rev Psychol 2001;52:83-110.

132. Liu LL, Lawrence JM, Davis C, et al.; SEARCH for Diabetes in Youth Study Group. Prevalence of overweight and obesity in youth with diabetes in USA: the SEARCH for diabetes in youth study. Pediatr Diabetes 2010;11:4-11.

133. Libman IM, Pietropaolo M, Arslanian SA, LaPorte RE, Becker DJ. Changing prevalence of overweight children and adolescents at onset of insulintreated diabetes. Diabetes Care 2003;26:2871-5.

134. Kaminski BM, Klingensmith GJ, Beck RW, et al.; Pediatric Diabetes Consortium. Body mass index at the time of diagnosis of autoimmune type 1 diabetes in children. J Pediatr 2013;162:736-740.e1.

135. Redondo MJ, Rodriguez LM, Haymond MW, et al. Serum adiposityinduced biomarkers in obese and lean children with recently diagnosed autoimmune type 1 diabetes. Pediatr Diabetes 2014;15:543-9.
136. Wilkin TJ. The accelerator hypothesis: weight gain as the missing link between Type I and Type II diabetes. Diabetologia 2001;44: 914-22.

137. Redondo MJ, Rodriguez LM, Escalante M, O’Brian Smith E, Balasubramanyam A, Haymond MW. Beta cell function and BMI in ethnically diverse children with newly diagnosed autoimmune type 1 diabetes. Pediatr Diabetes 2012;13:564-71.

138. Goran MI, Bergman RN, Cruz ML, Watanabe R. Insulin resistance and associated compensatory responses in african-american and Hispanic children. Diabetes Care 2002;25:2184-90.

139. Danielson KK, Drum ML, Estrada CL, Lipton RB. Racial and ethnic differences in an estimated measure of insulin resistance among individuals with type 1 diabetes. Diabetes Care 2010;33:614-9.

140. Kostraba JN, Cruickshanks KJ, Neville TG, et al. Clinical characteristics of IDDM in Hispanics and non-Hispanic whites. Little evidence of heterogeneity by ethnicity. Diabetes Care 1992;15:1303-9.

141. Betancourt JR, Green AR, Carrillo JE, Ananeh-Firempong O II. Defining cultural competence: a practical framework for addressing racial/ ethnic disparities in health and health care. Public Health Rep 2003;118: 293-302.

142. Palau-Collazo MM, Rose P, Sikes K, et al. Effectiveness of a Spanish language clinic for Hispanic youth with type 1 diabetes. Endocr Pract 2013;19:800-4.

143. Kim MT, Han HR, Song HJ, et al. A community-based, culturally tailored behavioral intervention for Korean Americans with type 2 diabetes. Diabetes Educ 2009;35:986-94.

144. Mauldon M, Melkus GD, Cagganello M. Tomando Control: a culturally appropriate diabetes education program for Spanish-speaking individuals with type 2 diabetes mellitus-evaluation of a pilot project. Diabetes Educ 2006;32:751-60.

145. Shaibi GQ, Konopken Y, Hoppin E, Keller CS, Ortega R, Castro FG. Effects of a culturally grounded community-based diabetes prevention program for obese Latino adolescents. Diabetes Educ 2012;38:504-12.

146. Bender MS, Nader PR, Kennedy C, Gahagan S. A culturally appropriate intervention to improve health behaviors in Hispanic mother-child dyads. Child Obes 2013;9:157-63.

147. Fitzgibbon ML, Stolley MR, Schiffer L, Van Horn L, KauferChristoffel K, Dyer A. Hip-Hop to Health Jr. for Latino preschool children. Obes (Silver Spring) 2006;14:1616-25.

148. Moore LL, Lombardi DA, White MJ, Campbell JL, Oliveria SA, Ellison RC. Influence of parents' physical activity levels on activity levels of young children. J Pediatr 1991;118:215-9.

149. Frerichs L, Brittin J, Robbins R, et al. SaludABLEOmaha: improving readiness to address obesity through healthy lifestyle in a Midwestern Latino community, 2011-2013. Prev Chronic Dis 2015;12:E20.

150. White House Task Force on Childhood Obesity. Let's Move: America's Move to Raise a Healthier Generation of Kids, 2015. (http://www.letsmove. org.).

151. Taveras EM, Gillman MW, Kleinman KP, Rich-Edwards JW, RifasShiman SL. Reducing racial/ethnic disparities in childhood obesity: the role of early life risk factors. JAMA Pediatr 2013;167:731-8.

152. Centers for Disease and Prevention, Division of Community Health. Racial and Ethnic Approaches to Community Health (REACH), 2015. (http://www.cdc.gov/nccdphp/dch/programs/reach/.).

153. Joslin Diabetes Center. Latino Diabetes Initiative, 2015. (http://www.joslin. org/joslin-latino-diabetes-initiative.html.)

154. Joslin Diabetes Center. Asian American Diabetes Initiative, 2015. (http:// aadi.joslin.org.). 